Revista de Filosofía y Teoría Política, n.o 48, 2017, e014, ISSN 2314-2553

Universidad Nacional de La Plata.

Facultad de Humanidades y Ciencias de la Educación.

Departamento de Filosofía

\title{
Karczmarczyk, P. El lenguaje privado a contrapelo, Buenos Aires- La Plata, EDULP, 2012, 370 páginas
}

\section{Fabiana Parra}

Universidad Nacional de La Plata - Instituto de Investigaciones en Humanidades y Ciencias Sociales/CONICET, Argentina

El lenguaje privado a contrapelo (2012) es la reelaboración de la investigación doctoral del Dr. Pedro Karczmarczyk, en la cual reconstruye las diferentes interpretaciones que constituyen la controversia filosófica, desatada con la publicación de las Investigaciones Filosóficas (IF) de Wittgenstein, acerca de la posibilidad de un lenguaje privado. En esta obra de 1953, el lenguaje privado aparece caracterizado como aquel donde "uno pudiera anotar y expresar sus vivencias internas- sus sentimientos, estados de ánimo, etc. para su uso propio” (ver IF § 243).Y también donde "las palabras deben referirse a lo que solo puede ser conocido por el hablante, a sus sensaciones inmediatas, privadas. Otro no puede, por tanto, conocer ese lenguaje”. (IF §258, citado en Karczmarczyk, 2012, p. 97).

Cabe recordar que la tesis de la privacidad lingüística tiene su origen en la filosofía moderna centrada en la subjetividad y la conciencia, lo que ha suscitado problemas vinculados al solipsismo y la representación del mundo. Frente a estas cuestiones, los intérpretes de L. Wittgenstein intentan encontrar una salida por la vía del lenguaje, enfocando la crítica del lenguaje privado en el aspecto epistemológico de las garantías, tal como la realizada por Malcolm, Fogelin, Kenny y Tugendhat, entre otros, colocando los problemas en otro nivel, pero no resolviéndolos. Con respecto a Malcolm, en el capítulo 3 del libro el autor señala que con su argumento se requieren instancias independientes de justificación que permitan decidir o establecer la corrección de los usos lingüísticos. Pero la independencia requerida no puede verificarse. Toda prueba, justificación, 
establecimiento, etc., está mediada por un estado mental. Con lo cual se pone de manifiesto que el criterio opera como un presupuesto del lenguaje: "si hay lenguaje, hay determinadas condiciones que permiten justificar la realización de un juicio de corrección” (p. 108). Como han detectado los críticos, principalmente Ayer y Thomson-ver capítulo 4-, nunca sabemos si un criterio se aplica, a lo sumo nos parece que lo hace. Pero la posibilidad de otorgar significado a través de estados mentales subjetivos (lo que nos parece) es lo que está siendo discutido en el argumento contra el lenguaje privado. Con lo cual los críticos arriban al mismo punto "arrinconando al defensor del argumento contra el lenguaje privado en un dilema” (p. 124), pero tampoco constituyen una alternativa frente a los problemas que surgen con la propuesta de Malcolm.

El capítulo 5 del libro explora la interpretación escéptica de Fogelin, quien formula una paradoja y una solución escépticas en su libro Wittgenstein (1994), las cuales tienen importantes puntos de contacto pero también diferencias de peso con la interpretación de Kripke. Karczmarczyk detecta que de la paradoja escéptica de Fogelin, según la cual "una regla no puede determinar ningún curso de acción”, se sigue la conclusión escéptica de que "la idea de acuerdo o desacuerdo ha perdido su significación”. El presupuesto que genera la paradoja es, entonces, que "seguimos reglas por medio de una interpretación” (p. 128). En opinión de Fogelin, no tenemos más que un argumento en contra del lenguaje privado: el del entrenamiento; pero, tal como nos muestra el análisis del libro, este argumento, que tiene la forma de un escepticismo semántico epistemológico, "no alcanza más que para establecer la imposibilidad contingente de un lenguaje privado” (p. 139).

En el capítulo 6 se encuentra la interpretación semántica fuerte que presenta Kenny, quien postula que "recordar el significado correctamente es estar capacitado para mostrar cómo lo recordado es un significado” (p. 169). Sin embargo, Karczmarczyk muestra que la estrategia de Kenny-que intenta evitar comprometerse con el principio de verificación en alguna de sus variantes- supone ser capaz de justificar, con lo cual hace resurgir las dificultades clásicas en otro nivel.

En cuanto a Tugendhat, su interpretación semántica-confrontada a la de Kenny-es abordada en el capítulo 8 del libro. En la versión dinámica de Tugendhat se prueba que la gramática de nuestras expresiones es la de las expresiones del lenguaje ordinario: “estas, en consecuencia, pueden usarse para probar que nuestro lenguaje ordinario no es un lenguaje privado. Pero eso ya lo sabíamos” (p. 200, cursiva en original).Pues la reconstrucción que Tugendhat hace del argumento del lenguaje privado motiva a Wittgenstein a discutir la posibilidad de un lenguaje privado en las Investigaciones Filosóficas. Tugendhat acepta el círculo de la justificación en el planteo clásico, pero su error consiste en haber utilizado una premisa fáctica que permite disolverla dentro del mismo preguntando por su justificación.

Las dificultades de las críticas al lenguaje privado están generalizadas en la crítica de Barry Stroud (1968) a los argumentos trascendentales, al mostrar que éstos no son en última instancia diferentes del argumento antiescéptico (p. 211). El argumento trascendental se reduce, o bien a una premisa fáctica que indica que a veces conocemos que nuestros criterios han sido satisfechos, o bien a una especificación del significado de la noción de criterio (condiciones de significatividad). Así, se encuentran comprometidos con la elucidación del criterio de corrección en términos de condiciones necesarias y suficientes.

La estrategia de Stroud nos ayuda a identificar que tanto las versiones epistemológicas (Malcolm, 
Fogelin), como las semánticas (Kenny, Tugendhat), buscan refutar el lenguaje privado explicitando ciertos criterios de significatividad que exceden el lenguaje privado, porque están implícitos en las preguntas del escéptico y en las afirmaciones del privatista. Stroud muestra que para que esta estrategia nos lleve más allá del lenguaje privado se requiere, o bien la cláusula de una premisa fáctica que indica que conocemos, o bien la especificación del conocimiento como una nota definicional de las condiciones elucidadas.

En este recorrido Karczmarczyk logra mostrar que en las diversas interpretaciones se constituye "la articulación de un supuesto que tiene lugar en la discusión acerca del lenguaje privado, como su remoción y las consecuencias de la misma” (p.34).Luego señala que en la interpretación de Saúl A. Kripke $\underline{1}$ tiene lugar una transformación en el planteo del argumento, en particular en relación con la manera de entender el concepto de criterio de corrección. La interpretación propuesta por Kripke logra eludir las dificultades en cuestión, al advertir que la refutación del lenguaje privado requiere abandonar toda la concepción del realismo, que afecta por igual al lenguaje privado y al público. Su propuesta no se apoya en la cuestión epistemológica, sino en la semántica-tal como lo evidencia su conocida "solución escéptica”, al establecer que los juicios de corrección solo tienen sentido en el marco de una comunidad uniforme en sus juicios-, lo que le permite superar los conflictos de las lecturas anteriores y abrir nuevos horizontes a los estudios del lenguaje y lo social, colocando al discurso filosófico en un terreno más fértil. De acuerdo con la lectura que hace Kripke, hay claramente una ruptura entre los supuestos que valen durante el desafío escéptico y los que valen en la solución escéptica. La crítica realizada por Wittgenstein-recogida en la interpretación de Kripke a la “concepción epistemológica clásica”, en la cual los significados se presentan como continentes de la aplicación de una regla guiada por un estado mental- involucra la noción de obediencia a ciegas, que da cuenta de la infinidad de aplicaciones de una regla, mientras que la dimensión social da cuenta de la normatividad de las prácticas con reglas en el marco de un juego de lenguaje (capítulo 2). En el abordaje de Kripke, el objeto de crítica wittgensteiniano ya no es una manera de considerar las condiciones de significatividad, sino la propia idea de significatividad sobre la que se constituiría el significado. De lo que se trata ahora es de clarificar las condiciones bajo las cuales el discurso normativo produce efectos.

Con este libro Karczmarczyk nos aporta valiosas herramientas para seguir profundizando en uno de los grandes debates del campo de la filosofía del lenguaje, y nos invita a agudizar la mirada crítica para pensarlos problemas filosóficos.

\section{Notas}

1Kripke, S. A. (2006).A propósito de reglas y lenguaje privado. Madrid: Edit. Tecnos [Título original: Wittgenstein on Rules and Private Language, publicada originalmente en 1982por Blackwell Publishing Ltd., Oxford] 